\title{
Finite Element Analysis of Cylindrical and Spherical Concrete Vaults
}

\author{
Parag Kumar ${ }^{1}$ | Shilpa $S^{2}$
}

${ }^{1}$ Students, Civil Engineering Department, Srinivas University college of Engineering and Technology, Mukka Mangaluru, Karnataka , India

${ }^{2}$ Assistant Professor, Civil Engineering Department, Srinivas University college of Engineering and Technology, Mukka Mangaluru, Karnataka, India

To Cite this Article

Parag Kumar and Shilpa S, "Finite Element Analysis of Cylindrical and Spherical Concrete Vaults", International Journal for Modern Trends in Science and Technology, Vol. 06, Issue 06, June 2020, pp.:70-75; https://doi.org/10.46501/IJMTST060616

Article Info

Received on 26-April-2020, Revised on 25-May-2020, Accepted on 30-May-2020, Published on 07-June-2020.

\section{ABSTRACT}

Concrete shell structures, often cast as a monolithic dome or stressed ribbon bridge or saddle roof. The thin concrete shell structures are a lightweight construction composed of a relatively thin shell made of reinforced concrete, usually without the useof internal supports giving an open unobstructed interior. This project aims to investigate the displacement and to find the maximum shear stress of cylindrical and spherical concrete vaults subjected to pressure load and it's self-weight. Boundary condition is given for the concrete vaults as simply supported. Concrete vaults of $3 \mathrm{~m}, 6 \mathrm{~m}$ and $9 \mathrm{~m}$ span and of length $8 \mathrm{~m}$ with same loading conditions were applied. If the shear stress is more it is easy to resist the more load on it. ANSYS results shows that the displacement values when compared with cylindrical and spherical shells, Spherical shells can resist more load.

KEYWORDS: Spherical vault, cylindrical vault, pressure load

Copyright (C) 2014-2020 International Journal for Modern Trends in Science and Technology

DOI: https://doi.org/10.46501/IJMTST060616

\section{INTRODUCTION}

Structural designers are an ewbreed of engineers, who act as bridges between conventional structural engineers and architects. Their role requires them to formulate the best possible design based on certain requirements, which depends on several factors. Thus, it is fair to say that they define the backbone of project. This causes a lot of responsibilities to fall on the designer. A good structural designer tries to incorporate several factors to make a complete design. This includes taking into account aesthetic, structural and constructional factors. This approach obviously causes several obstacles, which can cause complications in the design process. This makes it imperative for a structural designer to have intuition and foresight, along with good structural knowledge to deal with these problems. It remains the primary responsibility of the structural designer to ensure that the structure performs all the functions, it was meant to perform before the start of the design process. The design process of any structure ultimately determines its 'structural life'. This motivates a designer to check the behaviour of the structure, when it is in a state of service. In the past, some shell structures have collapsed due to increasing influences of nonlinear parameters. 
Structural failure is the biggest night mare of any designer. Shells experience something called 'snap - back' behavior, which is characterized by sudden loss in load carrying capacity, leading to immediate failure. Furthermore shells collapse without warning, unlike other structures which show consider able visual deformations before collapse. This warning is unavailable to shell designers adding more significance to checking nonlinear effects in the design process. Now, finite element softwares can be used to incorporate such effects in computational design. Together with numerous available modeling softwares, they provide the most essential tools for a structural designer.

\section{OBJECTIVES OF THE PROJECT}

- The numerical investigations are to determine the confinement effects and behaviour of concrete vaults due to internal wall pressure load and to investigate andstudy by applying different available structural systems for minimizing the deflection under lateralloading.

- To estimate the ultimate strength and study thebehaviour of concrete vaults and To develop stress plots for various span for different shapes of a concrete vaults subjectedto pressure loadingconditions.

- Responses of different structural systems are studied in terms of displacements due to cylindrical and spherical shapes.

\section{METHODS ANDMETHODOLOGY}

For the analysis, ANSYS 15 was used for the concrete vaults having length $8 \mathrm{~m}$ and height of the vaults varied between $2.4 \mathrm{~m}$ and $6 \mathrm{~m}$.

Boundary condition is given for the concrete vaults as simply supported. To ensure the both ends are simply supported for the concrete vaults, all degree of freedom is selected. The inner wall of the concrete vaults pressure of $7890.73 \mathrm{MPa}$ was applied and self-weight was applied on the concrete vaults.

Table. 1 Material Properties

\begin{tabular}{|c|l|c|c|}
\hline Property Name & Symbol & Values & Units \\
\hline Grade & $\mathrm{fck}$ & 20 & $\mathrm{~N} / \mathrm{mm}^{2}$ \\
\hline $\begin{array}{c}\text { Young's } \\
\text { Modulus }\end{array}$ & $\mathrm{E}$ & 22.36 & $\mathrm{GPa}$ \\
\hline Poisson ratio & $v$ & 0.19 & --- \\
\hline Density & $\rho$ & 2500 & $\mathrm{~kg} / \mathrm{m}^{3}$ \\
\hline
\end{tabular}

\section{VALIDATION OFMODEL}

Validation model consists of a steep catenary earth brick shells having particular dimension. The material and geometric properties for these finite element (FE) models are as follows: Young's modulus $=6,200 \mathrm{MPa}$, Poisson's ratio $=$ 0.2 ,Density $=1,950 \mathrm{~kg} / \mathrm{m}^{3}$, Thickness $=250 \mathrm{~mm}$, Span $=6 \mathrm{~m}$, When comparing these loads, that the steepest catenary vault $(\mathrm{H} / \mathrm{R}=2.0)$ carries approximately $40 \%$ of the load over a flat roof covering the same plan area by ANSYS and 35\% according to the journal.

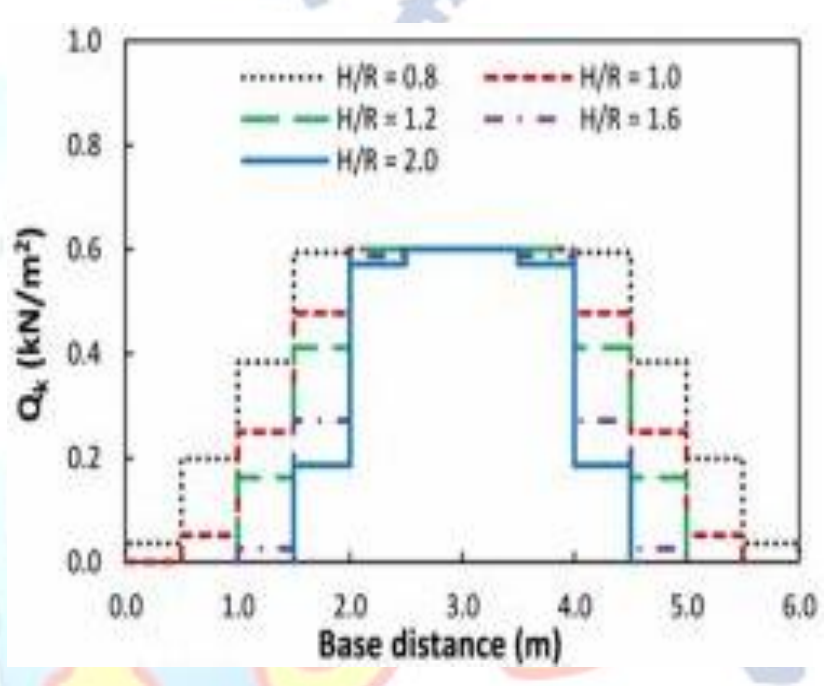

Fig. 1 Imposed loading: Inaccessible roof

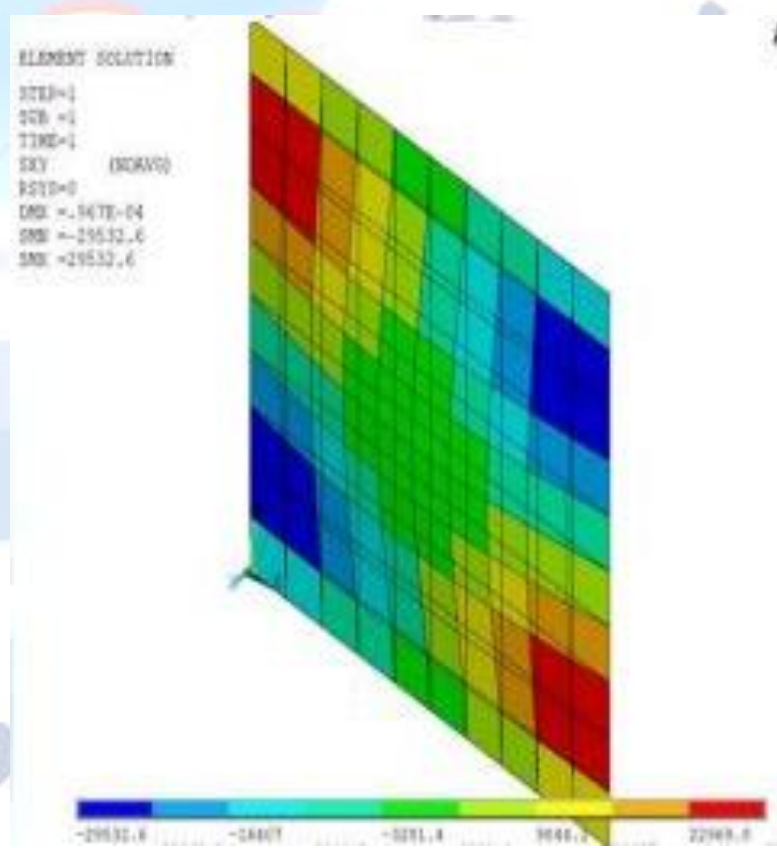

Fig.2 Flat roof stress in xy direction 


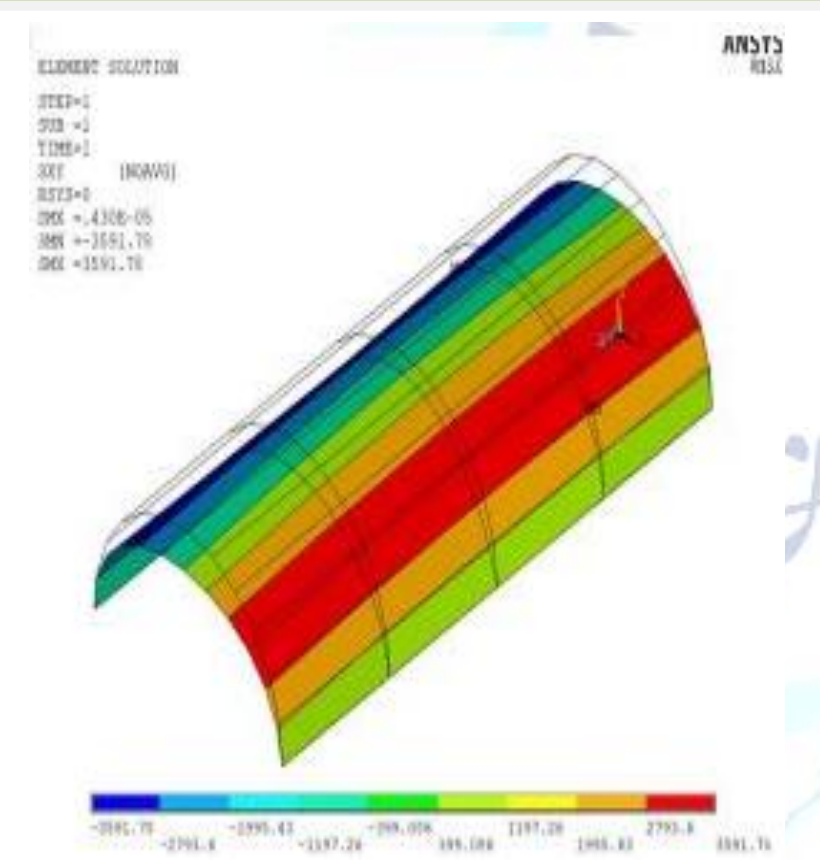

Fig 3 Cylindrical stress at xy direction vault roof

\section{RESULTS AND DISCUSSIONS}

For the simulations carried out, we found shear stress and displacement in $\mathrm{x}$ direction, $\mathrm{y}$ direction and xy direction having span $3 \mathrm{~m}, 6 \mathrm{~m}$ and $9 \mathrm{~m}$ for cylindrical and spherical concrete vaults, among these xy direction shown the better results.

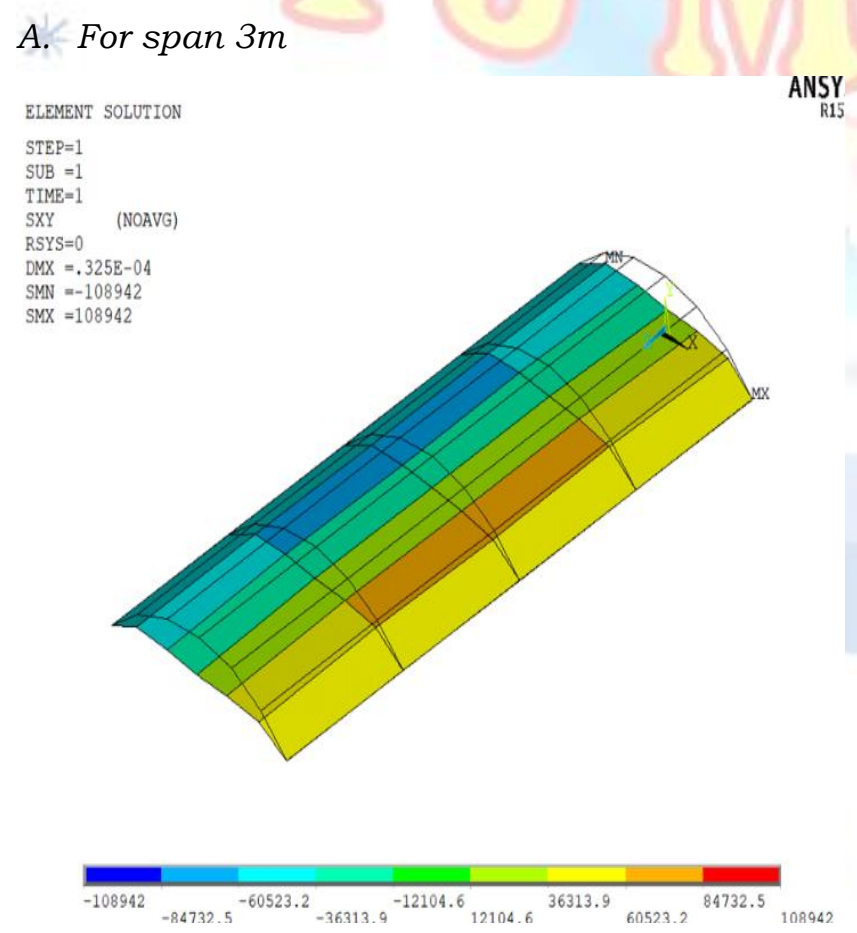

Fig.4 Cylindrical shell of 3m span; XY shear stress

Fig. 4 shows a concrete cylindrical shell of $3 \mathrm{~m}$ span and length $8 \mathrm{~m}$. From ANSYS software, there is a displacement of $0.325 \times 10-4 \mathrm{~mm}$ in a cylindrical shell and shear stress is equal to $108942 \mathrm{~N} / \mathrm{m}^{2}$

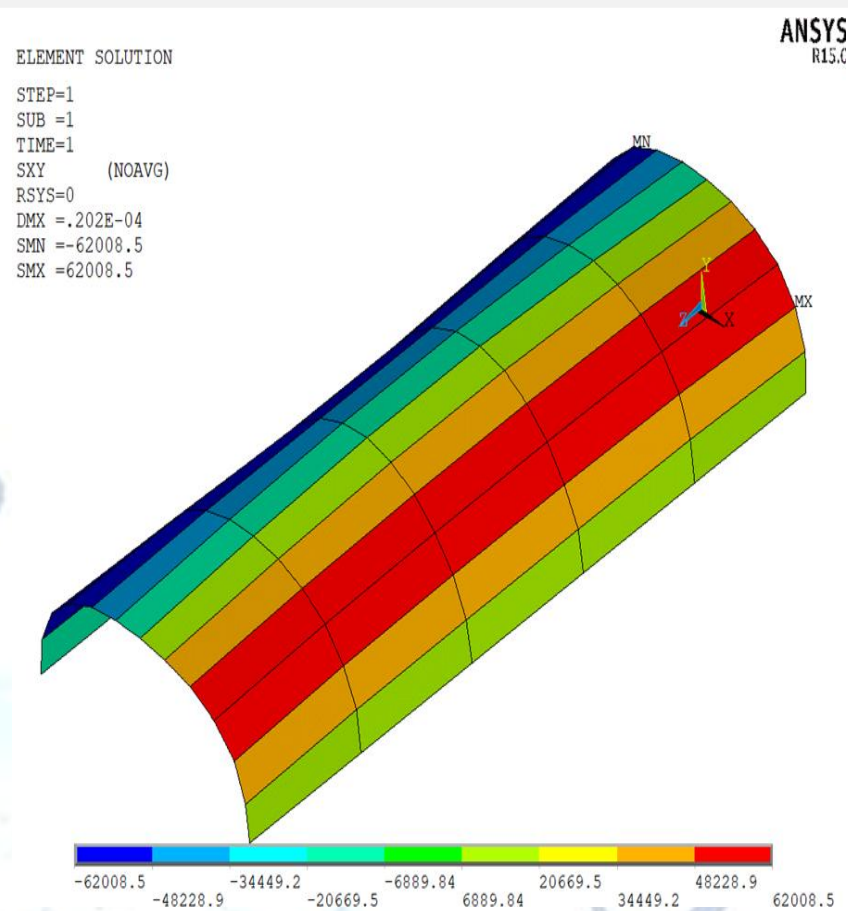

Fig.5 Spherical shell of 3m span; XY shear stress

Fig. 5 shows a concrete spherical shell of $3 \mathrm{~m}$ span and length $8 \mathrm{~m}$. From ANSYS software, there is a displacement of $0.202 \times 10^{-4} \mathrm{~mm}$ in a spherical shell and shear stress for $3 \mathrm{~m}$ span is equal to $62008.5 \mathrm{~N} / \mathrm{m}^{2}$

B. For span $6 m$

ELEMENT SOLUTION
STEP $=1$
SUB $=1$
TIME $=1$
SXY $\quad$ (NOAVG)
B.SYS $=0 \quad$
DMX $=.137 \mathrm{E}=03$
SMN $=-193776$
SMX $=193776$

AIVIJ R15.0



Fig. 6 Cylindrical shell of $6 \mathrm{~m}$ span; XY shear stress

Fig. 6 shows a concrete cylindrical shell of $6 \mathrm{~m}$ spanand length $8 \mathrm{~m}$. From ANSYS software, 
there is a displacement of $0.137 \times 10^{-3} \mathrm{~mm}$ in a cylindrical shell and shear stress for $6 \mathrm{~m}$ span is equal to $193776 \mathrm{~N} / \mathrm{m}^{2}$
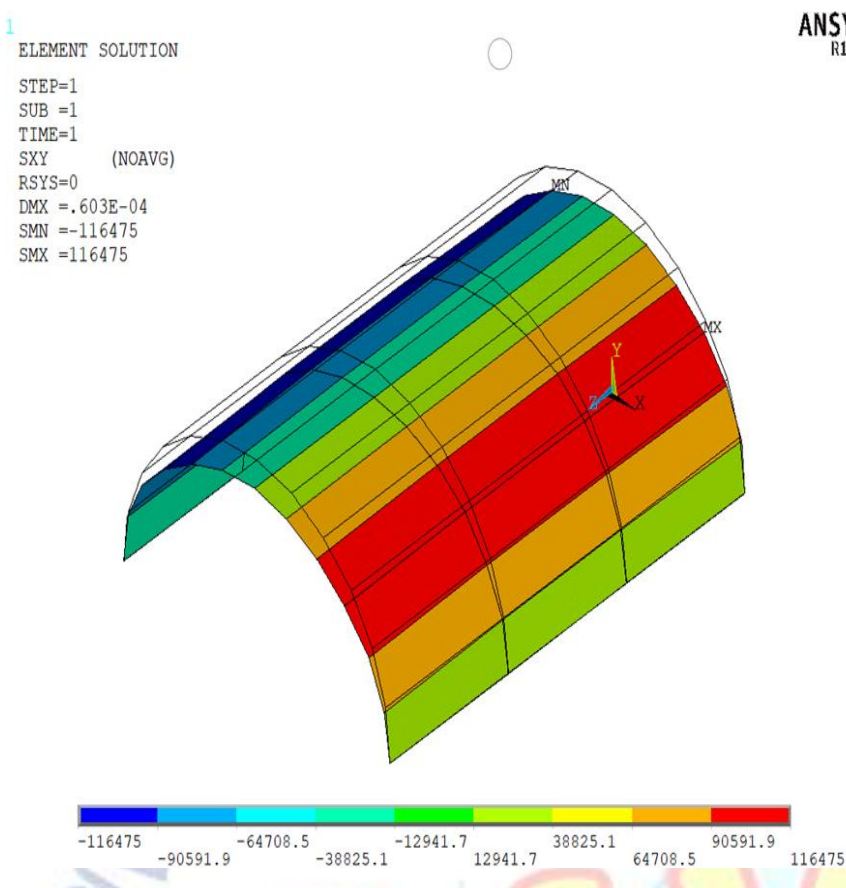

Fig.7 Spherical shell of $6 \mathrm{~m}$ span; XY shear stress

Fig. 7 shows a concrete spherical shell of $6 \mathrm{~m}$ span and length $8 \mathrm{~m}$. From ANSYS software, there is a displacement of $0.603 \times 10^{-4} \mathrm{~mm}$ in a spherical shell and shear stress for $6 \mathrm{~m}$ span is equal to $116475 \mathrm{~N} / \mathrm{m}^{2}$

\section{For span $9 m$}
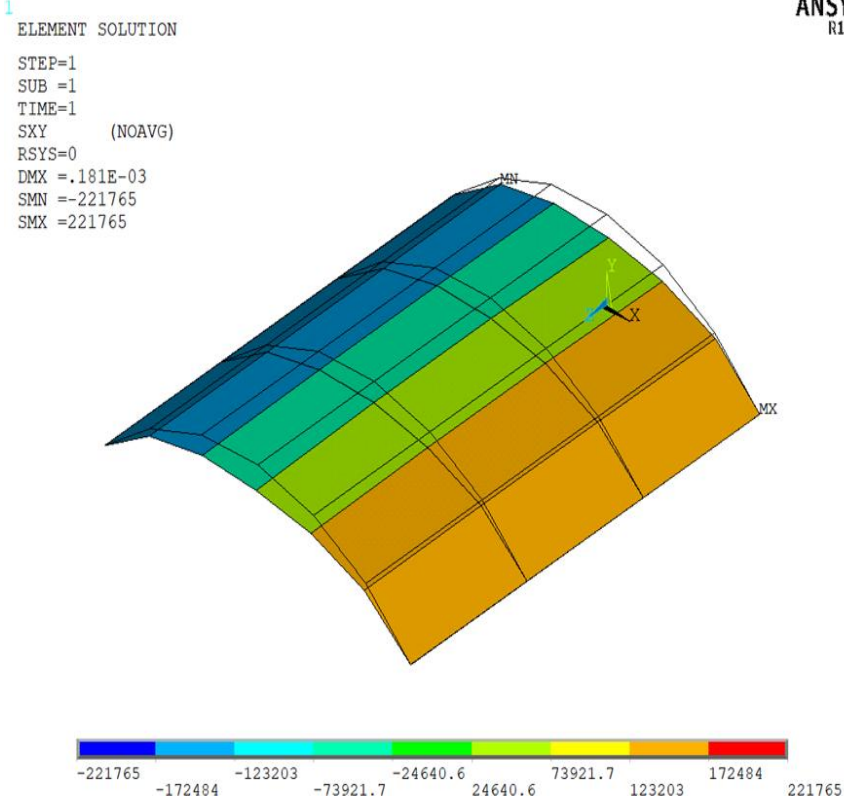

Fig. 8 Cylindrical shell of $9 \mathrm{~m}$ span; XY shear stress

Fig. 8showsaconcretecylindricalshellof9mspana ndlength $8 \mathrm{~m}$. FromANSYSsoftware, the reisa displacement of $0.181 \times 10^{-3} \mathrm{~mm}$ in a cylindrical shell and shear stress for $9 \mathrm{~m}$ span is equal to $221765 \mathrm{~N} / \mathrm{m}^{2}$

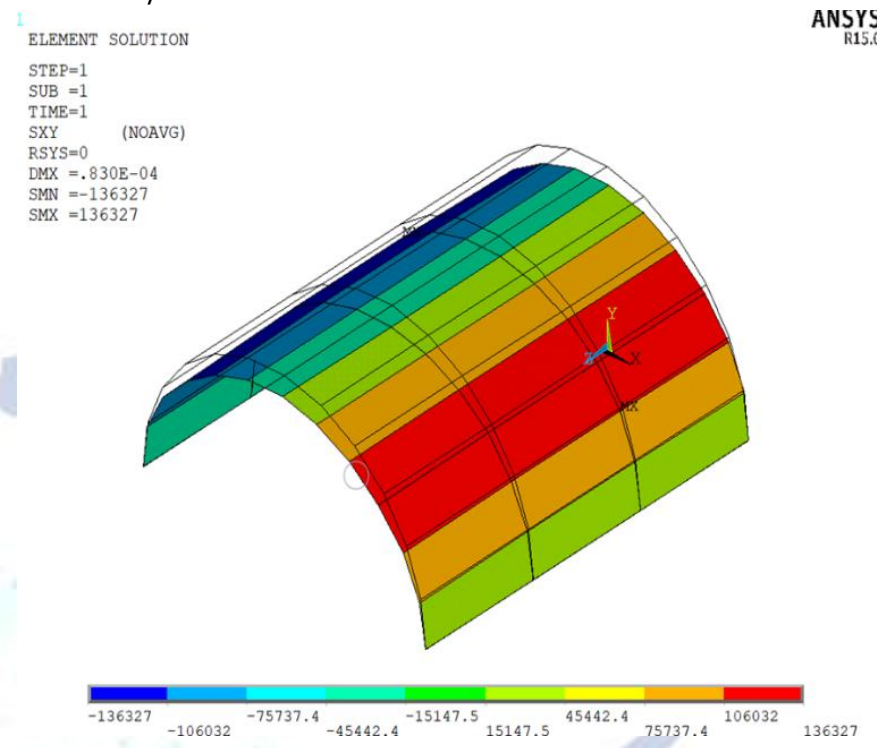

Fig. 9 Spherical shell of $9 \mathrm{~m}$ span; XY shear stress

Fig. 9 shows a concrete spherical shell of $9 \mathrm{~m}$ span and length $8 \mathrm{~m}$. From ANSYS software, there is a displacement of $0.830 \times 10^{-4} \mathrm{~mm}$ in a spherical shell and shear stress for $9 \mathrm{~m}$ span is equal to $136327 \mathrm{~N} / \mathrm{m}^{2}$

\section{CONCLUSION}

Based on above discussions, it can be concluded that the designed roof is a esthetically pleasing, structurally efficient and easy to construct.

- ANSYS results shows that the displacement values when compared with cylindrical and spherical shells. Spherical shells can resist more load.

- Shear stress is zero, indicates no forces are acting in $\mathrm{Y}$ direction for both cylindrical and spherical shells.

- While comparing Shear stress acting in X direction for both cylindrical and spherical shells. Cylindrical shells has less stress values.

- Von Mises criterion is one which states the equivalent distortion of energy of a stress, body attributes to yielding. The cylindrical shells yield more when compared with spherical shell.

- By comparing with $3 \mathrm{~m}, 6 \mathrm{~m}, 9 \mathrm{~m}$ span and same $\mathrm{H} / \mathrm{R}$ ratio, the use of cylindrical shells with increase in span, Von Mises stress increases in yielding value.

- Results of the analysis showed that shear stress is maximum along $\mathrm{XY}$ direction and along this direction it is able to resist the pressure load for a cylindrical shell.

- The spherical shell has captured the 
imagination of generations of builders proving the timeless beauty of the simplest of shapes. Cylindrical shell is an attempt to enhance the aesthetical efficiency of the roof system.

\section{REFERENCES}

[1] Mehdi S. Zarghamee and Andrew T. Sarawit, "Buckling of shallow spherical concrete domes under gravity and earthquake loads", Journal of Structural Engineering/Volume 146 Issue 5 - May 2020

[2] Gaurav Pandey, Mandeep Kaur Arora, Pranay Kumar Rahi, "Efficient design and detailed analysis of rcc dome", IJSRD - International Journal for Scientific Research \& Development| Vol.5,Issue 04, 2017 | ISSN (online): 2321-0613

[3] Dr. Nabeel Abdulrazzaq Jasim, Dr. Ihab Sabri Saleh, Dr. Saddam

KhalafFaleh"Structuralanalysisofribbeddomesusingfiniteel ement method", International Journal of Civil Engineering Research. ISSN 2278-3652 Volume 8, Number 2 (2017), pp.113-130

[4] Ms. M. A. Jain, Prof. C. B. Nayak, Prof. S. B. Walke, "Parametric study of dome: a review", IJSRD - International Journal forScientific Research \& Development| Vol. 4, Issue 03, 2016 | ISSN (online): 2321-0613

[5] Yousry B.I. Shaheen1, Boshra A. Eltaly 2, Amany A. Hanesh, "Experimental and fe simulations of ferrocement domes reinforced with composite materials", Concrete Research Letters,Vol.5(4)2014

[6] Wail N Al-Rifaie, Azad Ahmed, "Experimental investigation on thin ferro cement dome structures", International Journal of Engineering and Advanced Technology (IJEAT) ISSN: 2249 -8958,Volume-3, Issue-2, December2013

[7] R. Pathak, A. Melani, R.K. Khare and V.K. Shukla, "Nonlinear seismic analysis of reinforced concrete cylindrical barrel vault structures", Proceedings of International Conference on Advances in Architecture and Civil Engineering (AARCV 2012), 21st - 23rd June 2012 260 Paper ID SAM113, Vol.1
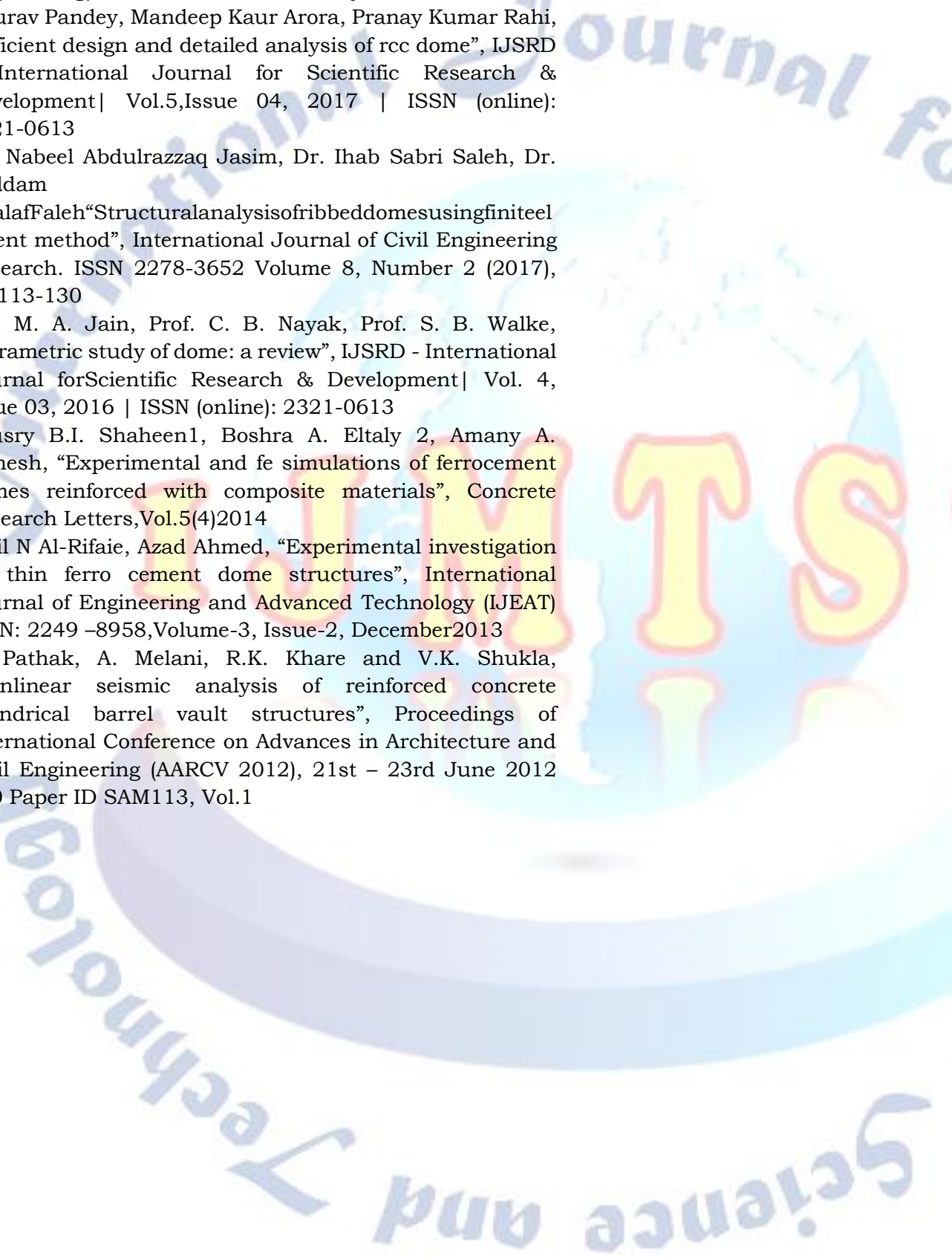